\title{
The European Defence Agency and Permanent Structured Cooperation: Are we heading towards another missed opportunity?
}

\section{Introduction}

The Member States' military capability deficits are well known. These can be attributed to nationally focused investment which leads to duplication and non-interoperability, the lack of a fully-fledged European strategic culture which would provide top-down guidance as to which capabilities need to be developed and finally Member States' static and declining defence budgets. Attempts to close the EU's numerous military deficits have been haphazard and have often been no more than a documenting exercise where capability gaps are identified but little is done to actually close them (the ECAP process being a case in point).

Nonetheless, there are significant financial imperatives for moving towards a greater use of pooling due to the current economic crisis. This article therefore analyses the work of the European Defence Agency (EDA) in military capability development and in particular focuses on the role that Permanent Structured Cooperation in Defence (PSCD) can play to encourage the Member States to move from defence sovereignty to pooled defence resources. ${ }^{1}$ Two interconnected research questions provide the core focus for the research. 1. What does PSCD add to what currently exists and to what extent is this likely to re-invigorate capability development? 2. To what extent can the EDA play a role in developing PSCD thus enabling the concept to succeed? Indeed, the introduction of PSCD in the Treaty of Lisbon can be seen as another "perceived opportunity' ${ }^{2}$ for the EU Member States to finally begin to address their capability gaps. Nonetheless, whether significant change actually materialises will depend upon how such a concept is implemented in practice and the mechanisms in place within the EDA to formalise and encourage cooperation. 
A recent attempt at what is partly envisaged under PSCD can already be highlighted by the EU Battlegroups which have not yet been deployed despite opportunities to do so. This highlights a major hurdle in increasing the EU's actorness because whilst PSCD might act as a mechanism to close capability gaps it is not a mechanism to overcome political willingness problems. Indeed it is argued that the Battlegroups provide a warning for PSCD in that only capabilities which are useful and most importantly usable should be developed. Finally, it highlights that conflicting visions of European security ${ }^{3}$ including when and where force is used has impacted upon the political willingness to use the Battlegroups - divisions which will form the basis of discussions on the formation of PSCD.

Nonetheless, convergence is beginning to take place as highlighted in the European Security Strategy, ${ }^{4}$ which combined with the albeit limited learning from military operations which have occurred in addition to the long term vision already carried out within the $\mathrm{EDA}^{5}$ offers a rough roadmap for capability development. Indeed we argue that the EDA has the potential to be a champion of PSCD, particularly in relation to the operationalisation of the concept. To offer a full insight into how these conflicting visions impact on the work of the EDA and capability development, strategic culture will be used. A security community's strategic culture provides its policy-makers with a range of beliefs, attitudes and norms concerning what actions are appropriate within the security and defence field which subsequently shapes their perceptions of defence issues. These relate to when, where and how force is used and provide an insight as to the extent to which differences between the Member States impact on the EU's actorness in defence. Therefore strategic culture enables a top down approach to capability development to be created which begins with what the EU wants to do in the world and then which capabilities need to be created to fulfil this rather than a bottom up approach. This would involve Member States looking at what capabilities they possess and then 
deciding what they can do with these as there is no strategic culture to provide guidelines which shape what action the EU might take.

The article concludes that despite conflicting visions of European security, advances have been made to close capability gaps more recently, including the idea of a European Air Transport Fleet and a Future Transport Helicopter initiative. This highlights that pooling has become a more popular option in addressing Member States' capability deficits. This underlines that PSCD, with the EDA acting as a pooling enabler, has the ability to be a success as a tool for capability development. Nonetheless, the Battlegroups provide a timely reminder that only tools which are needed and can be used flexibly should be developed. If the Member States fail to improve their military capabilities through such mechanisms as PSCD, this would represent a missed opportunity further denting the EU's image as a global security actor.

\section{European Strategic Culture}

This article posits that due to the lack of a fully fledged strategic culture, agreement on when, where and how force is used is only in its infancy and as such has hindered EU defence efforts. Therefore, military capability development through the EDA has been weak as Member States prefer national initiatives. Additionally, without an agreement on what role the EU should play, it is difficult to be decisive concerning which military capabilities to acquire.

Strategic culture has been utilised from both a country and EU perspective. It can be defined as the beliefs, attitudes and norms towards the use of force, held by a security community which has had a 'unique historical experience'. ${ }^{6}$ Of central importance is the interpretation of these historical experiences which as Berger states are 'transmitted through socialization; and by providing individuals with cognitive maps, they serve as filters through which subsequent 
events and experiences are apprehended'. ${ }^{7}$ Whilst strategic culture emphasises continuity over change, this does not mean that the concept is static. Change can occur in response to events in the external security environment, although this is not automatic as a strategic culture once socialised is also institutionalised. As Meyer highlights 'norms are so stable because they are often institutionalised in laws, policies and power structures'. ${ }^{8}$ These institutionalised beliefs and values can impact upon which policy options are available. As such, strategic culture acts as a lens through which external security issues are considered relevant or otherwise. The most profound changes occur in reaction to war and conflict. In this instance a country's strategic culture is replaced with another. Normally, however, change only occurs incrementally in response to new security conditions such as $9 / 11 .^{9}$ In this instance two or more parts of a strategic culture come into conflict with each other which leads to a realignment.

However whilst this framework certainly fits for a sovereign country, to what extent is it possible for an organisation such as the EU to have a strategic culture? CSDP is governed by unanimity decision-making and therefore it is the Member States who make the decisions concerning which military missions to participate in, whether to sign up to political security documents such as the European Security Strategy or the Headline Goal 2010 and to what extent they will use the EDA for capability development. Thus the perspective taken here is to look at convergence and divergence between the EU Member States ${ }^{10}$ as opposed to looking at strategic culture from an EU perspective. ${ }^{11}$ Nonetheless, how much convergence actually has to take place? The EU does not need to have a strategic culture akin to an EU Member State which is involved in a multitude of international security organisations and have national security interests outside of the EU sphere. Instead an EU strategic culture should be seen as an additional layer which lies on top of national strategic cultures. As Meyer states 'a European strategic culture is not taking the place of national strategic cultures, but it should 
be conceived of primarily as the increasing institutionalisation of those ideas, norms and values that are sufficiently shared at the national level' ${ }^{12}$ Therefore some convergence has to take place concerning the EU's use of military force.

Knowing what military tasks the EU should conduct, where operations should be conducted and which other organisations the EU should work with (e.g. the UN and NATO) is crucial for military capability development. As Cornish and Edwards highlight, this is 'in order to rationalize the acquisition of capabilities necessary for the range of humanitarian and peacekeeping tasks envisaged. Equally, without military capabilities, all talk of a strategic culture would ring hollow'. ${ }^{13}$ Whilst convergence has taken place between the EU Member States concerning the security threats that the EU is facing, as highlighted in the European Security Strategy, there is no agreement concerning how they should be dealt with. This has led to ad hoc decision-making concerning potential military operations. Although the beginnings of a European strategic culture can be seen, it has not developed fully enough to act as a guide for the use of military capabilities.

A lack of a fully fledged strategic culture, leads to a suboptimal CSDP. In essence, military missions that are too complex or too high in intensity, which could result in casualties, are unlikely to be agreed. In other words civilian operations are more likely to be deployed than military ones. Divergences regarding the use of force impact how and which military capabilities are to be acquired. In this respect, the creation of PSCD is intended to act as a motor for the development of more effective and robust military capabilities in the EU something which the EDA has not been able to do so far. Thus the successful operationalisation of PSCD is seen as an important factor for developing the 'Defence' component of the EU and hence for contributing to a more optimal CSDP. Bátora highlights that 'the EDA has been a flashpoint of institutional logics representing different visions of 
how various aspects of defense integration in the EU should be organized'. ${ }^{14}$ These differences have led to the evolution of a number of divisions in the EU in this respect, which are directly linked to the development of an EU strategic culture in security and defence. These divisions can be summed up as follows:

Atlanticism vs. Europeanist approaches - this impacts upon what capabilities should be developed and where these capabilities should be bought from. Does a more Atlanticist vision lead to a greater reluctance to work through the EDA and an inclination to buy American?

- Regional vs. Global approach to security and defence - in particular this encompasses how willing Member States are to use force outside of Europe, which in turn is based on their strategic culture. Divisions concerning this field impact upon such areas as strategic airlift and sealift which are needed for missions outside of the region.

- Pro-active on the use of force vs. Restrictions concerning the use of force - i.e. which tasks should military capabilities be created for? This relates to the type of operations that the EU would be prepared to carry out i.e. should the EU aim for mostly lowlevel, less demanding, 'last resort' instruments or high-end and more demanding military operations geared towards pre-emptive engagement?

- Defence sovereignty vs. Pooled defence resources ${ }^{15}$ - do Member States want to buy nationally or go through the EDA in order to pool defence capabilities with other EU Member States? In other words, on the one hand there are those Member States who would prefer that the defence industry including research and development (R\&D) in addition to armaments production remain nationally geared towards self-sufficiency and self reliance. On the other hand are those Member States who would prefer that defence, armaments and $\mathrm{R} \& \mathrm{D}$ are conducted in the framework of a common 
endeavour - transnational projects, common standards and joint procurement programmes. $^{16}$

These four dimensions will be used as key factors to ascertain the extent to which an EU strategic culture in security and defence has developed and how far this matters for providing an explicit top-down approach to military capability development through the EDA and PSCD. Three of these dimensions reflect the key tenets of strategic culture, namely 'when', 'where' and 'how' the EU uses force. 'When' refers to pro-active vs. restrictions on the use of force; 'Where' - to a regional vs. global approach to security and defence; and 'How' to Atlanticist vs. Europeanist approaches. Additionally, Atlanticist vs. Europeanist approaches and defence sovereignty vs. pooled defence resources impact whether PSCD will function at the practical level. If Member States prefer to buy American or do not wish to pool due to national preferences then PSCD will not be successful. Thus all four dimensions set the parameters for the successful or unsuccessful functioning of PSCD.

\section{Developing PSCD}

PSCD is a new tool for capability development which is part of the Lisbon Treaty and previously the European Constitution. It allows for groups of Member States who are military able and politically willing, to enhance their military capabilities including the ability to contribute to a Battlegroup. ${ }^{17}$ To meet these objectives, Article 2 of the protocol on PSCD specifies five areas of action. These include: agreeing on objectives for the level of investment in defence equipment; bringing defence apparatus into line with each other as far as possible, by harmonizing the identification of military needs, by pooling, and where appropriate specialisation; to enhance force availability, interoperability, flexibility and deployability by setting common objectives regarding the commitment of forces; addressing shortfalls identified by the Capability Development Mechanism and taking part where 
appropriate in equipment programmes within the EDA. ${ }^{18}$ The decision to establish PSCD can be taken by qualified majority voting as opposed to unanimity voting, making the mechanism easier to establish, at least on paper.

PSCD is meant to add to what already exists through the establishment of a high level of criteria thus ensuring that capability development is structured. ${ }^{19}$ Indeed for the first time within the area of CSDP, a binding leverage will be introduced, meaning that PSCD constitutes a very rare opportunity. ${ }^{20}$ This is because participating Member States would have to meet a number of objectives aimed at the improvement of military capabilities or would have to leave PSCD. Thus the potential for meaningful capability development through PSCD is very real. It would add value through increasing cost effectiveness, multinational cooperation, assessment, increased sustainability and finally inclusiveness and flexibility in reaching the criteria. ${ }^{21}$ Thus PSCD should encourage the Member States to move from defence sovereignty towards pooled defence resources. Indeed for all Member States, apart from France and the UK, PSCD makes sense due to the pooling element although it should be stated that not all small and medium Member States are in favour. ${ }^{22}$ This is particularly the case in the context of the current financial crisis where defence budgets are under pressure. Therefore PSCD acts as a way of acquiring essential capabilities at less cost. It could even be considered that all PSCD needs to be a success is to save money. ${ }^{23}$ Indeed this is the major attraction of PSCD. A report on PSCD by the West European Union also underlines this by emphasising that PSCD must be attractive which can be done by 'offering a sufficient return on investment to provide an incentive for the non-participating states to join it' ${ }^{24}$

To discuss PSCD, a seminar took place under the Spanish Presidency in mid March 2010 in Brussels. Whilst the Spanish have placed PSCD on the agenda, they have at the same time not taken the lead and instead were very careful regarding pushing the idea. ${ }^{25}$ Indeed there did not 
appear to be a champion for PSCD, be it a Member State or a group of Member States, capable of placing the issue on the agenda of the European Council, although there was the suggestion that the Weimar group could fulfil this role. ${ }^{26}$ Indeed there have been some preliminary reflections within the Weimar group regarding some initial basic ideas for PSCD. ${ }^{27}$ Under the Belgium Presidency in the second half of 2010, an assertive position on the issue has been taken, including a position paper by the next three holders of the Presidency - Belgium, Hungary and Poland as well as a seminar which took place on 13 July 2010. This was attended by 120 national experts. ${ }^{28}$ Nonetheless, without one or more of the big Member State to get fully behind the initiative and give it some momentum, there is only so much the Belgians and Spaniards can do to push PSCD forward. ${ }^{29}$ Indeed the outcome of the Belgian Presidency was the Ghent initiative which made no mention of PSCD and instead focused on 'Pooling and Sharing'.

\subsection{Criteria for PSCD}

A number of issues still remain to be resolved before PSCD can be initiated. These essentially revolve around the criteria which should be put in place when establishing PSCD. First, will there be one PSCD or several relating to different capabilities? In essence, the idea is to have one PSCD and within that there will be clusters of Member States. Each participating state will be able to decide on the types of projects it wants to take part in and how to cooperate, but all states will abide by a common set of criteria. ${ }^{30}$ It is important to note, that PSCD should be as inclusive as possible. In this respect, the more participating Member States, the more synergies and effects of scale which can be created. ${ }^{31}$ Additionally to make PSCD selective would create a two tier EU in defence. Hence, there would be no incentive for those in the second league to increase their military capabilities. ${ }^{32}$ Thus as Herz states, 'it is important to find a middle ground between too loose criteria for membership to the PSCoop [PSCD] which would defeat its point of faster integration, and too constricting criteria which 
would reduce the number of Member States involved'. ${ }^{33}$ Indeed it is this concern over exclusion which has led to some Member States' negative opinion of PSCD.

To alleviate this problem, criteria should be fulfilled by a specific date rather than be a condition of initial entry. Biscop and Coelmont have suggested that participating Member States (pMS) should increase their deployability and sustainability by an agreed $\%$ and by an agreed deadline. ${ }^{34}$ They should also try to harmonize their defence expenditures, contribute in ratio of their GDP to EDA-initiative projects and contribute to all CSDP operations requiring military assets. Nonetheless, is it realistic to demand that participating Member States have to put up capabilities for every operation? This in particular relates back to divergences between the EU Member States' strategic cultures concerning a regional vs. global approach to security and defence and pro-active on the use of force vs. restrictions concerning the use of force. In other words, for political reasons, Member States do not necessarily want to contribute to every military operation. Therefore, whilst Member States can be encouraged to participate in military operations using equipment developed through PSCD, they would reject any strongly binding commitment in this direction. ${ }^{35}$ This implies that participating Member States would reject criteria which forced them to contribute to every EU military operation.

Nonetheless, as the Belgian, Hungarian and Polish position paper points out PSCD 'should form a Top-Down approach, aim at improving the required defence capabilities - including armament and $\mathrm{R} \& \mathrm{~T}$ - that are needed for conducted the most demanding operations. In other words, the structured cooperation should be considered as a process ultimately leading to convergence'. ${ }^{36}$ In this respect PSCD is seen as a process which will lead to convergence and thus to a stronger European strategic culture. However the report by the Belgian Presidency on the seminar which occurred was less enthusiastic about this aspect. It highlighted that 
PSCD will not fix 'the absence of consensus regarding a common strategic view on CFSP/CSDP 37 and instead recommended producing a European Grand Strategy or White Book. Thus the question remains as to whether PSCD will be an adequate vehicle to create processes of convergence. Indeed greater convergence needs to materialise before a White Book could be created. In this respect the replacement of PSCD with 'Pooling and Sharing' appears to represent a downgrading of what Member States are willing to do. Nonetheless, the Ghent Initiative has produced some momentum in enabling the Member States to find additional areas in which to initiate pooling and sharing initiatives without it being seen to be an exclusive club meaning that it is more open and usable. ${ }^{38}$ Therefore "pooling and sharing" could represent a vehicle with which PSCD can eventually be operationalised.

\subsection{The Implementation of the EU Battlegroup Concept: A Warning for PSCD?}

How successful is PSCD likely to be and will it facilitate the top down approach which is currently missing from CSDP? One way of assessing this and to highlight its pitfalls is through the EU Battlegroup Concept which can be seen as a de-facto or operational form of PSCD. ${ }^{39}$ A Battlegroup comprises 1500 armed force personnel and can be formed either unilaterally or multinationally. ${ }^{40}$ Evidently it is the multinational aspect which makes the Battlegroups a form of PSCD as a group of EU Member States (in addition to third countries) can come together to form a Battlegroup i.e. a type of rapid reaction capability. For all Member States, apart from France, Italy and the UK, coming together to create a Battlegroup is the only feasible way of contributing to the concept, highlighting that only through pooling can Member States participate. Moreover, there is just one concept, with one set of criteria and within that, a number of different groupings or clusters, which is exactly how PSCD is envisaged. Additionally there is also an element of flexibility in the Battlegroup Concept as it is up to the participating Member States concerning exactly how a Battlegroup is formed. 
This includes the type of assets that each Member State provides, which again ties in with PSCD.

On paper, the Member States are committed to the Battlegroup Concept, as evidenced by the fact that 25 out of 27 Member States plus four non-EU countries are participating. However, the fact remains that the Battlegroups have yet to be deployed despite discussions on three occasions regarding their potential usage. There are primarily two reasons for the Battlegroups lack of deployment which interconnect with PSCD. First is that the Battlegroups are simply too small and are therefore unable to fill mission remits, including the size and scope of operations as occurred for Congo in 2006 and Chad in $2008 .^{41}$ Whilst PSCD is there to create capabilities which then feeds into a mission, it does highlight the problem regarding the connection between creating capabilities and their usefulness. Thus PSCD will not add any value if it is not in line with the capabilities that are needed. ${ }^{42}$

The second area concerns political willingness and in particular relates to the divergences between the Member States concerning a regional vs. a global approach to security and defence which can be influenced by their views on when force should be used (i.e. pro-active on the use of force vs. restrictions concerning the use of force). In this respect, some countries such as Germany have restrictions on the use of force and do not have immediate defence interests in Africa for example. Meanwhile others such as the UK and France have a global approach to security, exemplified by their willingness to engage militarily in a number of theatres outside of the European continent. Due to the fact that the Battlegroups rotate every six months, whether a mission using the Battlegroups would go ahead depends on whether it is in a participating Member State's interest to deploy. Interestingly, Germany has rejected the use of the Battlegroups in the Congo in 2006 and in 2008. Indeed there is concern among 
German policy-makers that France is using CSDP to upload its post-colonial responsibilities to the EU level. ${ }^{43}$

This issue also has the potential to affect PSCD. After creating the capabilities, will the Member States actually deploy them? Whilst it might appear that this issue has the ability to affect the Battlegroups more than PSCD due to the former's rotational nature, the same might also occur in PSCD if Member States decide to specialise or if a group of likeminded states come together to create the same capability. This is due to the fact that one country could block the use of a particular capability. ${ }^{44}$ Nonetheless, Biscop states that 'the more integrated Europe's military capabilities will be, the more EU Member States will be pushed to act as one'. ${ }^{45}$ From this perspective, inclusivity is key to preventing PSCD from suffering the same problems as the Battlegroups. This is particularly so in the context of a lack of any strategic defence document detailing where the EU's interests actually lie. However without any binding commitment regarding equipment on the ground in operations, it is difficult to see how this will overcome political willingness problems in the context of PSCD.

Although it might appear that the Battlegroups have failed in their current form, the concept has succeeded in generating additional capabilities in some Member States as highlighted by Jacoby and Jones ${ }^{46}$ in the case of Sweden. Indeed whilst joining both the Battlegroups and PSCD is voluntary, peer pressure ensures participation. As Biscop states in relation to PSCD "the desire to "be in" will probably lead many others to participate. Once in, peer pressure and to avoid exclusion for no longer fulfilling the criteria should stimulate Member States' efforts'. ${ }^{47}$ Indeed participating Member States could use PSCD to fill capability gaps in their Battlegroups and in achieving the criteria for PSCD, some Member States could use a Battlegroup. However, it should be underlined that the two are not automatically connected and that the Battlegroups should be seen as one potential way of achieving PSCD targets. ${ }^{48}$.To 
sum up, the Battlegroups act as a warning for PSCD. If PSCD is not to be yet another missed opportunity in the story of European security and defence and if it is to fulfil its potential, then the Member States must ensure that only capabilities which are required and usable are created. This needs to be built on a top down approach to security, encompassing when and where Member States should use force in an EU context.

\section{The EDA: a champion for PSCD?}

\subsection{Governance and project areas}

The European Defence Agency was established in July 2004 with a Council Joint Action 2004/551/CFSP of the Council of Ministers with the idea of providing for better coordination and harmonisation of defence cooperation among the Member States in the framework of the CSDP. Building on previous (unsuccessful) ideas for the creation of such a body ${ }^{49}$ and prompted by an array of economic and identity-related factors, ${ }^{50}$ the creation of the EDA became a reality after key Member States' preferences converged on the EU level. ${ }^{51}$ After years of opposing the creation of an EU based Agency in the field of armaments, defence procurement and cooperation, Britain agreed with the French proposals for setting up such a body. ${ }^{52}$ Paris suggested that the new body will not be a traditional national armaments agency focused exclusively on defence procurement, but rather a 'capabilities agency', bringing together research, development, and procurement and providing the political framework for common European armament projects. Thus, it would also have an important political role to direct and evaluate Member States' progress towards fulfilling their capability commitments. ${ }^{53}$ The deal between the UK and France was signed at their bilateral summit in Le Touquet, in February 2003. The initiative was then agreed at the EU level, with the European Council at Thessaloniki supporting it in December 2003 and the Council of Ministers formally establishing the European Defence Agency with a Joint Action in July 2004. 
The Agency has been operational ever since, but only two years ago the Treaty of Lisbon codified it, thus giving it an explicit legal personality. Under Art. $28 \mathrm{~d}(1 \& 2)$, the EDA has a number of tasks: to identify and evaluate common military capability objectives; to promote the harmonisation of operational needs and the adoption of procurement methods; to propose multilateral projects and ensure the coordination of the respective programmes; to support and coordinate EU level defence research and development activities; to improve the effectiveness of military expenditure within the EU; and identify measures for strengthening the industrial and technological base of the defence sector.

The Agency currently has 26 participating Member States. ${ }^{54}$ It carries out its tasks in liaison with the Commission and its statute, seat and operational rules are determined by a Council decision based on a QMV procedure. ${ }^{55}$ Thus, it introduces a number of supranational elements in the defence field. These include the establishment of a common pool of information, the development of common standards that promote greater harmonization and "more coherence and integration in defence cooperation among EU Member States".56 However the EDA fundamentally remains an intergovernmental body. Having limited mandate and power from the Member States, geared mostly towards producing and providing information to them and being governed by ministers or governmental appointees, the EDA clearly exhibits characteristics of a classic inter-governmental agency. ${ }^{57}$ It is headed by the High Representative of the Union for Foreign Affairs and Security Policy (HR) - currently Baroness Catherine Ashton - who is responsible for its overall functioning. She also ensures that the strategic direction provided by the EU Council and the decisions of the EDA's Steering Board are correctly implemented by the Chief Executive. The Steering Board is chaired by the HR, consists of the EU Defence Ministers (or their representatives) and operates within the political framework provided by the Council of Ministers. Among other 
things, it adopts the Agency's general budget, appoints the Chief Executive (on a proposal from the Head of the Agency); adopts the EDA rules of procedure and takes decisions by QMV. Its personnel consists of national experts seconded by the Member States, staff recruited directly by the Agency under fixed-term contracts and a small number of Community officials. ${ }^{58}$

Between its creation and the coming into force of the Lisbon Treaty, the Agency has been active in establishing an armaments strategy, research and development strategy and industrial strategy. ${ }^{59}$ In 2005 most of the EDA participating Member States ${ }^{60}$ agreed on a Code of Conduct for Defence Procurement as a means towards the creation of an internationally competitive European Defence Equipment Market and strengthening the European Defence Technological and Industrial base. The main principles of the Code are: a voluntary, nonbinding approach; fair and equal treatment of suppliers; mutual transparency and accountability; mutual support; and mutual benefit. ${ }^{61}$ In October 2006 the Agency produced the 'Long-Term Vision' report, which was endorsed by European Union Defence Ministers at a meeting of the EDA Steering Board in Levi, Finland. This was the product of 11 months of study involving officials and experts from governments, defence bodies, academia and industry across Europe. ${ }^{62}$ Although it was a non-committing document it was important in that it provided directions for defence planners in all Member States on the military capabilities that will be required in the framework of the CSDP, related to the global security challenges facing Europe in the next 20 years. ${ }^{63}$

Based on this document, in 2007 the EDA's Capabilities Directorate identified several key areas for capability improvement and started working on a Capability Development Plan. ${ }^{64}$ Some of these areas include the development of 'Software Defined Radio' to improve interoperability across Member States, a 'Network Enabled Capability' to enhance the 
effectiveness of CSDP operations through a common communications and information network and Maritime Surveillance Network capabilities for the identification of small, highly mobile and threatening forces in open waters. Meanwhile, work in the area of 'Chemical, Biological and Nuclear Hazards' has encompassed toxic industrial materials in building capabilities for their detection, identification and monitoring. Finally two important areas have been identified by the Member States as critical to CSDP operations. The 'European Air Transport Fleet' aims to pool national airlift resources to enhance the EU's strategic air-lift capability, whilst the Future Transport Helicopter initiative and a helicopter training programme, will increase in-theatre mobility and build up capabilities for flying in demanding operational and environmental scenarios. ${ }^{65}$ In the context of these key areas the EDA currently provides the politico-strategic framework for the implementation of over 50 projects. Some of these are worth 50 million, others over 100 million euro. All projects are implemented by different constellations of members - from 4-5 to 20 participating states - and each works towards building respective sets of capabilities in the above identified key areas. ${ }^{66}$

The latest development involving the EDA as the venue for political dialogue happened namely in the context of the above mentioned Ghent Initiative. On 30 November 2011 the EU defence ministers met in the framework of the EDA's Steering Board to endorse a package of eleven areas for cooperation under the logo of 'Pooling and Sharing', ranging from 'medical field hospitals' and 'air-to-air refuelling' to 'smart munitions' and 'naval logistics' with the first projects starting already in December 2011. ${ }^{67}$ Indeed, the Polish Presidency has been pushing the development of CSDP including 'Pooling and Sharing'.

\subsection{The EDA's role in the operationalisation of the PSCD}

In relation to $\mathrm{PSCD}$, the EDA does not have any decision making power for its actual operationalisation (this stays firmly within the PSC and the Council) but rather may have an 
expert say in its practical set up and further development. The EDA possesses an enormous database of all the projects and programmes of its participating Member States and could therefore provide the relevant information for setting up the criteria for PSCD. Based on that information, the EDA can also be useful for the actual implementation of the concept. In addition, the EDA is supposed to give a regular assessment of the PSCD participating Member States' contributions with regards to identified capability needs for the operationalisation of PSCD ${ }^{68}$ Also, thanks to its expert know-how it can provide regular evaluation of its practical implementation. In particular, it can be useful in identifying shortfalls in capability standards and suggesting ways to tackle them. ${ }^{69}$

Another important function of the EDA in the operationalisation of PSCD is that it may provide a useful forum for political dialogue. It is realistic to assume that initially not all EDA Member States will become participants in PSCD but still the EDA may provide a framework for transparent dialogue between both the participating and non-participating states. Some consider that this may lead to greater socialisation in the domain of joint capability development and thus alleviate some of the existing divisions and suspicions among the Member States. ${ }^{70}$ Moreover, this may also provide for greater accountability in PSCD matters. In this respect PSCD may in fact help in raising the profile of the EDA by making it more engaged and politically visible. Related to the latter, the very fact that the High Representative is also the chair of the EDA helps in raising its political visibility. ${ }^{71}$ In particular it may contribute towards the faster implementation of some of the most demanding projects, by generating the needed political and financial resources for this to happen. The EDA also has a strong potential to boost the civil-military interface in crisis management operations because the projects that are currently running - e.g. maritime surveillance, software defined radio, transport helicopter training - have value and potential usefulness for both the military and civilian domains. ${ }^{72}$ 
Finally, the financial aspects of a possible further integration in the defence field in the context of the PSCD are crucial insofar as this type of cooperation is seen as offering much better output for the input that the Member States would commit. This would mean mostly better deployable and better deployed forces and capabilities, including terminating redundant forces rather than wasting money in maintaining identical national capabilities. ${ }^{73}$ For its part, the EDA can encourage higher savings among the Member States through promoting joint projects on EU level and hence greater pooling of resources. Without a completely new mechanism for encouraging savings in defence matters further integration in this field in the EU would inevitably become harder. In this respect the Defence Ministers meeting in Brussels on 30 November which endorsed the start of eleven cooperative projects is a point of attention. The importance of this meeting is that it happened in the midst of the worst financial crisis experienced by the EU Member States since the introduction of the "Euro" and as such, it underlined the need for cooperation and savings of scale by means of pooling and sharing in the defence field. During the meeting, the EDA's current Chief Executive Ms. Claude-France Arnould was explicit in this respect, appealing for a "top-down direction to put in place a cooperative way of working" and endorsing Pooling and Sharing as "part of the solution" of the Member States' current budgetary challenges. ${ }^{74}$

All in all, the EDA can be seen as a facilitator that prompts the Member States to cooperate and participate in joint projects, and hence it can play an important role in operationalising PSCD. ${ }^{75}$ However, the main question regards whether the EDA manages to capitalise on its potential to contribute to the PSCD project - having in mind the existence of a number of issues regarding Member States' motivation to fully work through the EDA.

\section{Key problem areas}


Similarly to the difficulties in operationalising the Battlegroup Concept, some of the main problems facing the EDA relate to the issue of political will. In particular they point to two of the earlier identified divisions among the Member States: defence sovereignty vs. pooled defence resources; and Europeanist vs. Atlanticist approaches to security and defence. The other two divisions - regional vs. global approach; and pro-active on the use of force vs. restrictions concerning the use of force - are also relevant, as they set the parameters within which the EDA and PSCD have to work. However, since this has been covered in section 2.2., the following sections build on this foundation by outlining the practical problems that occur in fully utilising the potential of the EDA which the first two divisions create.

Some consider that initially the EDA was more active and entrepreneurial, "more at the front" and hence more visible than today. ${ }^{76}$ Among the main reasons are the lack of a strong leadership and the gradual change in thinking among the EDA's staff - from the first generation which was more enthusiastic in starting the new project, to the current one which has a much more pragmatic attitude. ${ }^{77}$ However, the more acute problems facing the EDA are related to the following divisions among the EU Member States.

\subsection{Going European or remaining national?}

Firstly not all Member States see the added value in doing business through the EDA - i.e. by joining trans-national projects within its framework. As it is already known, one of the EDA's main goals is to support the creation of an internal EU defence market and integrated European defence industry, hence the principle of pooled defence resources. ${ }^{78}$ In 2006 the EDA adopted two important documents that provide the legal framework for such developments to occur - the 'Framework Agreement of Security of Supply' and 'Security of Information'. Both of these documents provide the necessary guarantees for the subscribing 
Member States that their defence needs will be fully met in the context of such an unprecedented intra-European pooling of resources.

However, seven years after the establishment of the EDA, the Member States have not moved too far in utilising its resources and prefer to continue with their national programmes which overlap in most cases. Reportedly, the national focus is predominant with ' 20 plus' national programmes existing in the field of procurement, research and the development of armaments. $^{79}$ Another example is given by Keohane and Valasek ${ }^{80}$ who report that in 2008 alone, there were 16 national programmes for the development of armoured vehicles run within the EU without any form of cooperation and coordination among the Member States. As the situation currently remains the same, this clearly exemplifies the logic of 'defence sovereignty', which is still present in the EU Member States. ${ }^{81}$ Although this creates serious duplication of efforts and financial resources, the Member States have not yet reached political consensus on relinquishing some and specialising in other capabilities, thus pooling resources more efficiently. This problem highlights the division of defence sovereignty vs. pooled defence resources and constitutes one of the most serious problems facing the work of the EDA and potentially the operationalisation of the PSCD concept. It is plausible to expect that some Member States may not wish to give up their defence sovereignty for pooling defence resources in the framework of PSCD. If this creates a situation in which a number of Member States permanently opt out from PSCD, this would certainly render the whole concept unsuccessful.

\subsection{Buying American or choosing European?}

Another acute problem facing the work of the EDA and again leading to weak political backing from the Member States is the division over the issue of Atlanticism vs. Europeanism regarding pooling armaments production, procurement, joint capabilities projects as well as 
the creation of a European defence industrial base. Political differences between Member States are specifically visible in the field of defence equipment acquisitions where the dilemma is to buy established American brands or available European alternatives. ${ }^{82}$ Batora observes that Denmark and the Netherlands already expressed interest in buying the USproduced Joint Strike Fighter instead of alternatives such as the Eurofighter (German-ItalianSpanish-British cooperation), Rafale (French) or Gripen (Swedish-British). ${ }^{83}$ Similarly, Kirchner and Sperling highlighted the traditionally strong UK interest in keeping their special relationship with the US intact. In their estimation, this together with "the ambition harboured by British military contractors to acquire the coveted status of prime contractor to the US Defense Department place additional limitations on the ability and willingness of the UK to deepen the integration of the European defence industrial base". ${ }^{84}$

Poland, meanwhile was accused of 'buying American' when Polish policy-makers decided to buy $48 \mathrm{~F}-16 \mathrm{~s}$ in 2003 , which incorporated a $\$ 3.8$ billion loan from the US, instead of investing in the European-made alternatives. As Longhurst and Zaborowski state, 'Poland's choice in defence procurement of US rather than European systems is a firm expression of Warsaw's Atlanticist credentials' ${ }^{85}$ Others are openly pragmatic, expressing the view that if NATO offers established and working standards in communication or equipment systems it would not be practical to create new standards and buy new systems. ${ }^{86}$ It should however be noted that the Poles are firm advocates of the EDA and have signed up to the EDA's code of conduct in addition to pledging ten million euros to the EDA's Defence R\&T Joint Investment Programme on Force Protection. Also they have recently purchased 23 helicopters from the 'Eurocopter' division of the European Aeronautics and Defence Company (EADS) ${ }^{87}$ and fully participate in the EDA's helicopter training programme. ${ }^{88}$ The question however is how far Atlanticist EU Member States such as the UK can begin to buy and sell European. The existence of hesitation and unwillingness on this issue demonstrates that even in the 
context of some level of institutionalisation of common structures (EDA) and standards (Code of Conduct on Defence Procurement) there is still an insufficient level of convergence of values and norms among the Member States regarding defence procurement.

Overall, the EDA can potentially have an actual added value to the PSCD concept but only when the Member States start pooling respective resources in more areas and find ways to balance the Europeanist and the Atlanticist approaches in this respect. Moreover, the EDA can be useful in the operationalisation of PSCD only if the latter is in line with the capabilities that are needed. If PSCD is driven by industry interests rather than the already identified priorities, the EDA would be able to add much less value to both the PSCD and the further development of the Common Security and Defence Policy. In the context of the weak convergence of values and norms among the Member States and aligning with a common European interest in defence procurement, and armaments production it seems that it is premature to talk about a sufficiently developed European strategic culture in this domain. This weakens both the potential of the Member States to operationalise PSCD and the ability of the EDA to act as a promoter of the new concept.

\section{Conclusion}

This article has highlighted the missing defence component - or the ' $D$ ' - in CSDP by analysing the lack of progress on military capability development thus far. It applied the concept of strategic culture including four closely related conflicting visions among the EU Member States concerning European security and defence. Within this, it has highlighted the work of the EDA and the extent to which PSCD can alleviate these problems. In so doing, it has underlined the problems of defence procurement and has used the Battlegroups to highlight the potential pitfalls of PSCD. 
The four conflicting visions were focused on: Atlanticism vs. Europeanist approaches, a regional vs. global approach to security and defence, pro-active on the use of force vs. restrictions concerning the use of force and defence sovereignty vs. pooled defence resources. Member States' geographical approach to defence and their approach to using force, impacts on political willingness. This connects to whether Member States are willing to deploy the capabilities they have invested in, as well as which military procurement projects they will participate in. Relating to this, the Battlegroup Concept highlighted that whilst Member States were committed to the concept on paper, deploying them was an issue for countries such as Germany which has restrictions on the use force and a more regional approach to defence. In this respect, PSCD provides an opportunity for military capability development but does not avoid the obstacle of Member States failing to deploy the capabilities that have been created due to a lack of defence interests.

The other two divisions directly impact the work of the EDA in actually acquiring the necessary military capabilities. A predominant number of Member States prefer to invest in national programmes in the field of procurement, research and development of armaments. Some Member States have consistently taken their relations with the US into account when deciding on which military capability to purchase. Others have demonstrated an explicitly pragmatic approach when deciding on particular defence equipment acquisition plans. This hardly bodes well for a concept such as PSCD which is based on pooling and thus implies a move from defence sovereignty to pooled defence resources. PSCD requires as many Member States as possible to be involved in order to get the economies of scale and interoperability which are required. The question remains as to whether PSCD will end up as a lowest common denominator concept, where the criteria are set by the least willing participating Member State rather than by the information provided by the EDA. This is particularly 
important as this information is based above all on the capabilities which are needed and are thus useful rather than political criteria.

By examining four areas of conflicting views of European security, this article has highlighted that a European strategic culture is not advanced enough to provide a top down approach to military capability development. Instead a bottom up approach would most likely remain in the foreseeable future whereby action is based on what capabilities are available within each Member State rather than being shaped by what role the EU should be playing. Nonetheless, will PSCD enable the Member States to go beyond this? By acting in union and pooling resources, participating Member States will be forced to look at when and where these capabilities should be used. Indeed, this is a necessity to ensure that PSCD does not become another 'missed opportunity' in the story of the development of CSDP. However, in the context of an insufficiently developed EU strategic culture in defence and the lack of active leadership for promoting PSCD it seems that the concept might not be operationalised any time soon, underlined by the move to 'Pooling and Sharing' which has seemingly replaced PSCD. In this respect, while the EDA may continue its work successfully in that military capabilities will be developed, the ' $\mathrm{D}$ ' will still be missing. 


\section{Notes}

${ }^{1}$ See J. Bátora, 'European Defence Agency: A Flashpoint of Institutional Logics', West European Politics 32/6 (2009).

${ }^{2}$ M. Burch, P. Hogwood, S. Bulmer, C. Carter, R. Gomez, and A. Scott 'Charting routine and radical change: A Discussion Paper', Manchester Papers in Politics, Devolution and European Policy Making Series No. 6 (2003), p8.

${ }^{3}$ Bátora (note 1) pp.1075-1098.

${ }^{4}$ Emil Kirchner and James Sperling, EU Security Governance (Manchester: Manchester University Press 2007), p.244.

${ }^{5}$ N. Witney, 'Re-Energising Europe's Security and Defence Policy' (London: European Council on Foreign Relations 2008); European Defence Agency. An Initial Long-Term Vision for European Defence Capability and Capacity Needs. (2006), via URL http://www.eda.europa.eu/genericitem.aspx?id=146, accessed 9. Dec. 2009.

${ }^{6}$ C. S. Gray, 'Strategic Culture as Context: The First Generation of Theory Strikes Back', International Affairs 7/1 (1999), pp. 51-52.

${ }^{7}$ Thomas Berger, Cultures of Antimilitarism: National Security in Germany and Japan (London: The John Hopkins Press 1998), p. 10.

${ }^{8}$ Christoph O. Meyer, The Quest for A European Strategic Culture: Changing Norms on Security and Defence in the European Union (New York: Palgrave Macmillan 2006), p.25.

${ }^{9}$ Kerry Longhurst,. Germany and the Use of Force (Manchester: Manchester University Press 2004), p. 20.

${ }^{10}$ See Meyer (note 8).

${ }^{11}$ A. Toje, 'A Strategic Culture for Europe. EU Security Policy after Iraq', Oxford Journal on Good Governance 2/1 (2005); J. Rogers, 'From 'Civilian Power' to 'Global Power': Explicating the European Union's 'Grand Strategy' Through the Articulation of Discourse Theory', Journal of Common Market Studies 47/4 (2009), pp. 831-862.

${ }^{12}$ Meyer (note 8) p.7.

${ }^{13}$ P. Cornish, and G. Edwards, 'The Strategic Culture of the European Union: a Progress Report', International Affairs 81/4 (2005), p.802.

${ }^{14}$ Bátora (note 1) p.1076.

${ }^{15}$ See Bátora (note 1).

${ }^{16}$ Bátora (note 1) p. 1082. 
17 'The Treaty of Lisbon' Official Journal of the European Union C306, Vol. 50, (17 December 2007), pp. 1534.

${ }^{18}$ Ibid, pp.154-155.

${ }^{19}$ Confidential interviews with a think tank expert and an official (Brussels 2010) - This article is based on 7 semi-structured, confidential interviews with think-tank experts, EU and national officials held between April and July 2010. We are grateful for their time and insights and fully respect their anonymity. Any mistakes and omissions remain ours.

${ }^{20}$ Confidential interview with an official (Brussels 2010).

${ }^{21}$ Confidential interview with a think tank expert (Brussels 2010).

${ }^{22}$ Whilst Belgium and Austria are for, Ireland, the Netherlands and Slovakia are against . Confidential interview with a think tank expert, Brussels, 2010.

${ }^{23}$ Confidential interview with an official (Brussels, 2010).

${ }^{24}$ West European Union. Permanent structured cooperation under the Lisbon Treaty - reply to the annual report of the Council. Document A/2074 (2010), p.5.

${ }^{25}$ Confidential interview with a think tank expert (Brussels 2010).

${ }^{26}$ Confidential interview with a think tank expert (Brussels 2010).

${ }^{27}$ Confidential interview with an official (Brussels, 2010).

${ }^{28}$ Belgian Presidency Council of the European Union. Position Paper by Belgium, Hungary and Poland on Permanent Structured Cooperation (2010), p. 1.

${ }^{29}$ Confidential interview with an official (Brussels, 2010).

${ }^{30}$ Confidential interviews with a think tank expert and an official (Brussels 2010).

${ }^{31}$ S. Biscop, and J. Coelmont, 'Permanent Structured Cooperation for Effective European Armed Forces', Egmont Security Policy Brief 9 (2010), p. 2.

${ }^{32}$ Confidential interview with an official (Brussels 2010).

${ }^{33}$ J. Herz, 2009. 'Military Capabilities - A Step Forward in ESDP?', ISIS Europe - European Security Review 46 (October 2009), p. 5.

${ }^{34}$ Biscop and Coelmont (note 31) pp. 2-3.

${ }^{35}$ Confidential interview with an official (Brussels, 2010).

${ }^{36}$ Belgian Presidency (note 28) p.2. 
${ }^{37}$ Belgian Presidency Council of the European Union. Seminar on Permanent Structured Cooperation (PESCO), Brussels (2010), p. 2.

${ }^{38}$ Confidential interview with a national official (Brussels 2011); European Defence Agency, Today's Ministers of Defence meeting: clear commitment for more Pooling \& Sharing projects (2011), Available at: http://www.eda.europa.eu/News/11-11-

30/Today_s_Ministers_of_Defence_meeting_clear_commitment_for_more_Pooling_Sharing_projects, [Accessed 14 December 2011]. For more information on the Ghent Initiative see S. Biscop, 'Pooling \& Sharing: From Slow March to Quick March?', Egmont Security Policy Brief 23, (2011).

${ }^{39}$ Confidential Interviews with a think tank expert and an official (Brussels 2010).

${ }^{40}$ For the typical layout of a Battlegroup see M. Kerttunen, 'The Concept', in M. Kerttunen, T. Koivula, and T. Jeppsson, eds. EU Battlegroup-Theory and Development in the Light of Finnish-Swedish Co-operation. Series 2, Research Reports No. 30 (Helsinki: Department of Strategic and Defence Studies, National Defence College 2005), via URL http://www.mpkk.fi/attachment/ad9d29e3539815313b364464a41b98a9/0379a258c9db18b7886e8066a0a5bb2a/ EU+Battlegroups, [accessed 12 June 2006], p. 30.

${ }^{41}$ W. Jacoby, and C. Jones, 'The EU Battle Groups in Sweden and the Czech Republic: What National Defense Reforms Tell Us about European Rapid Reaction Capabilities', European Security 17/2 (2008), p. 328.

${ }^{42}$ Confidential interview with an official (Brussels 2010).

${ }^{43}$ A. Menon, 'Empowering Paradise? The CSDP at Ten', International Affairs 85/2 (2009), p. 236.

${ }^{44}$ Confidential interviews with officials (Brussels, 2010).

${ }^{45}$ S. Biscop, Permanent Structured Cooperation and the Future of ESDP, Egmont Paper 20 (Gent: Academia Press 2008), p. 19.

${ }^{46}$ Jacoby and Jones (note 40).

${ }^{47}$ Biscop (note 45) p. 19.

${ }^{48}$ Confidential interview with a think tank expert (Brussels 2010).

${ }^{49}$ In 1978 Egon Klepsch MEP suggested the creation of an European Armaments Agency as a EU-only armaments body. In 1991 a Declaration calling for the creation of such an Agency was attached to the Maastricht Treaty. In both cases no practical steps followed, due to British and other pro-Atlanticist Member States' reservations on this issue - see Daniel Keohane, Europe's new defence agency. Policy Brief. (Centre for European Reform: London 2004); also G. Grevi and D. Keohane 'ESDP Resources', in G. Grevi, D. Helly and 
D. Keohane, (eds.) European Security and Defence Policy. The First 10 Years (1999-2009), (The EU Institute for Security Studies, Paris, 2009).

${ }^{50}$ Bátora (note 1) 1076.

${ }^{51}$ Grevi and Keohane (note 49).

${ }^{52}$ Keohane (note 49).

${ }^{53}$ Grevi and Keohane (note 49).

${ }^{54}$ Currently only Denmark does not participate.

${ }^{55}$ The Treaty of Lisbon, (note 17) Art 28d, 2.

${ }^{56}$ Bátora (note 1), 1075-77; and 1085

${ }^{57}$ Bátora (note 1) 1084.

${ }^{58}$ Council Joint Action on the establishment of the European Defence Agency, Official Journal of the European Union, L 245/17 (2004/551/CFSP of 12 July 2004).

${ }^{59}$ Alexander Weis, 'How European Defence Agency Becomes Increasingly Operational', Agence Europe (Exclusive Interview 13 October 2009).

${ }^{60}$ These include 25 Member States plus Norway. Of all the EU Member States, only Romania and Denmark do not participate - see European Defence Agency, Key Facts About the Code of Conduct on Defence Procurement, (Brussels, 01/10/2009) Available at: http://www.eda.europa.eu/genericitem.aspx?area=Organisation\&id=155, [Accessed 16 June 2010].

${ }^{61}$ European Defence Agency, The Code of Conduct on Defence Procurement, (Brussels, 21/11/2005), Available at: http://www.eda.europa.eu/genericitem.aspx?area=Organisation\&id=154 [Accessed 16 June 2010]

${ }^{62}$ European Defence Agency, An Initial Long-Term Vision for European Defence Capability and Capacity Needs, (2006), Available at: http://www.eda.europa.eu/genericitem.aspx?id=146, [Accessed 9 December 2009]. ${ }^{63}$ Ibid.

${ }^{64}$ Both the Long Term Vision and the Capability Development Plan are set in the context of the wider Comprehensive Capability Development Process that 'translates' in a systematic manner the politico-military requirements into actual capabilities - see European Defence Agency, Capabilities Development, (2007), Available at: http://www.eda.europa.eu/genericitem.aspx?area=Organisation\&id=115, [Accessed 9 December 2009].

${ }^{65}$ On this issue see: European Defence Agency (note 64); Agence Europe (note 59); and Confidential interview with an official (Brussels 2010). 
${ }^{66}$ Confidential interview, with an official (Brussels 2010).

${ }^{67}$ See European Defence Agency (note 38) .

${ }^{67}$ The Treaty of Lisbon (note 17) Art.3, 155.

${ }^{68}$ The Treaty of Lisbon (note 17) Art.3, 155.

${ }^{69}$ On this issue see: Confidential interviews, with an official; and think-tank expert (Brussels, 2010); Bátora

(note 1) 1084; and Belgian Presidency Council of the European Union. Position Paper by Belgium, Hungary and Poland on Permanent Structured Cooperation (2010) p. 4.

${ }^{70}$ Confidential interview with an official (Brussels, 2010).

${ }^{71}$ Confidential interview with a think tank expert (Brussels, 2010).

${ }^{72}$ Confidential interview, with an official (Brussels, 2010).

${ }^{73}$ Confidential interviews with think-tank experts (Brussels, 2010).

${ }^{74}$ Belgian Presidency (note 38) p. 4.

${ }^{75}$ Belgian Presidency (note 69) p. 4.

${ }^{76}$ Confidential interview with a think tank expert (Brussels 2010).

${ }^{77}$ Confidential interview with a think tank expert (Brussels 2010).

${ }^{78}$ European Defence Agency (note 61); see also European Defence Agency (note 58); and Bátora (note 1), p. 1087.

${ }^{79}$ Confidential interviews with think tank-experts, (Brussels, 2010); also Grevi and Keohane (note 49)

${ }^{80}$ Daniel Keohane and Tomas Valasek Willing and Able? EU Defence in 2020, (Centre for European Reform, London, 2008) p. 38.

${ }^{81}$ Bátora (note 1) p. 1086.

${ }^{82}$ Grevi and Keohane (note 49)

${ }^{83}$ Bátora (note 1) p. 1089.

${ }^{84}$ Kirchner and Sperling (note 4) p. 204-5.

${ }^{85}$ Zaborowski, M. and Longhurst, M. 'America's Protégé in the East? The Emergence of Poland as a Regional Leader', International Affairs, 79/5 (2003), p. 1011.

${ }^{86}$ Confidential interview with a national official (Brussels, 2010).

${ }^{87}$ The Eurocopter group was created in 1992 with the merger between the helicopter divisions of Aerospatialematra (France) and DaimlerChrysler Aerospace (Germany). It is now a subsidiary owned $100 \%$ by EADS. After several successive integrations, Eurocopter is, at present, composed of three entities: the parent company, 
Eurocopter, the German subsidiary, Eurocopter Deutschland; and the Spanish subsidiary, Eurocopter España see EADS, Eurocopter, an EADS company: Shareholders, (2010) Available at: http://www.eurocopter.com/site/en/ref/Shareholders_23-2.html, [Accessed 26 August 2010].

${ }^{88}$ Confidential interview with a national official (Brussels 2010). 